\title{
O MÉTODO ARQUETIPOLÓGICO E O ESTUDO DAS LITERATURAS INDÍGENAS E AFRODIASPÓRICAS
}

\section{THE ARCHETYPOLOGICAL METHOD AND THE STUDY OF INDIGENOUS AND APHRODIASPORIC LITERATURES}

\author{
Heliene Rosa da Costa ${ }^{1}$ \\ http://orcid.org/0000-0002-5138-3430
}

\begin{abstract}
Resumo: Intelectuais indígenas e afrodescendentes costumam ter o valor de suas produções literárias, muitas vezes, relativizado pela crítica tradicional, em razão de estabelecerem profundo vínculo com a oralidade. Entretanto, no mundo grego antigo, berço das civilizações ocidentais, temos notícias dos Aedos, poetas que cantavam hinos e canções, em complexa estrutura autoral: coletiva e com foco na oralidade. A literatura afrodiaspórica dá centralidade às histórias contadas como forma de transição da totalidade dos saberes, pela prática dos griôts. Da mesma forma, as culturas ameríndias recuperam as memórias ancestrais e promovem o fortalecimento da identidade cultural e espiritual pela contação de histórias. O método arquetipológico proposto por (DURAND, 1996) apresenta a vantagem de poder ser associado às diferentes culturas e povos, de maneira sistematizada que pode ser capaz de operacionalizar relações não excludentes entre diferentes aspectos, entre eles, a oralidade e a escrita. Do excerto, podemos concluir que, a partir do emprego desses processos investigativos, torna-se possível dirimir questões valorativas e estigmatizantes nas concepções de povos e culturas diferentes. A metodologia adotada nessa análise é pesquisa interpretativa e documental dos textos literários que compõem o corpus. Para as análises utilizamos autores como Durand, Esra Pound, Graça Graúna, Márcia Kambeba, Lia Minápoty, Conceição Evaristo, Cristiane Sobral, Kiusam de Oliveira, Sidarta Ribeiro e Muniz Sodré, entre outros.
\end{abstract}

\section{Palavras-chave: Método Arquetipológico; Literatura Indígena Contemporânea; Literatura Afrodiaspórica.}

\footnotetext{
Abstract: Indigenous and Afro-descendant intellectuals often have the value of their literary productions, often relativized by traditional criticism, because they establish a deep bond with orality. However, in the ancient Greek world, cradle of Western civilizations, we have news of Aedos, poets who sang hymns and songs, in a complex authorial structure: collective and focused on orality. Aphrodiasporic literature gives centrality to the stories told as a way of transitioning the totality of

${ }^{1}$ Doutora em Estudos Literários pela Universidade Federal de Uberlândia-UFU (2020). Docente de Português e Literaturas na Rede Municipal de Ensino de Uberlândia (RMEUDI-PMU-SME). Possui pesquisas acadêmicas e publicações nas áreas de Linguística e de Literatura Brasileira. Desenvolve projetos pedagógicos e literários e possui publicações artísticas de literatura e de poesia.
} 
knowledge, through the practice of griôts. Likewise, Amerindian cultures recover ancestral memories and promote the strengthening of cultural and spiritual identity through storytelling. The archetypological method proposed by (DURAND, 1996) has the advantage of being able to be associated with different cultures and peoples, in a systematized way that may be able to operationalize non-excluding relationships between different aspects, including orality and writing. From the excerpt, we can conclude that, from the use of these investigative processes, it becomes possible to resolve evaluative and stigmatizing issues in the conceptions of different peoples and cultures. The methodology adopted in this analysis is interpretative and documentary research on the literary texts that make up the corpus. For the analysis, we used as theoretical framework authors such as Durand, Esra pound, Graça Graúna, Márcia Kambeba, Lia Minápoty, Conceição Evaristo, Cristiane Sobral, Kiusam de Oliveira, Sidarta Ribeiro and Muniz Sodré, among others.

\section{Keywords: Archetypological Method; Contemporary Indigenous Literature; Aphrodiaspora Literature.}

\section{Considerações Iniciais}

A literatura permite abrir o campo das especulações acerca dos conceitos e das experiências que marcam a trajetória intelectual humana. Uma amplidão que se desdobra e possibilita vislumbrar diferentes facetas dela própria, seja no campo epistemológico, social, ideológico ou metalinguístico. As narrativas revelam as maneiras como cada cultura elabora suas inquietações e seus deslumbramentos acerca dos fatos e das diferentes visões do mundo.

Nesse aspecto, hoje é notório que intelectuais indígenas e afrodescendentes têm o valor de suas produções literárias, poéticas e artísticas, muitas vezes, relativizado pela crítica tradicional, em razão de estabelecerem profundo vínculo com a oralidade. Enquanto isso, do mundo grego antigo, temos notícias dos Aedos, poetas que cantavam hinos e canções, mormente, improvisados, em uma complexa estrutura autoral: coletiva e com foco na oralidade.

Assim, encontramos em (CABRAL, 2004, p.78) o seguinte relato: "Na 'Disputa entre Homero e Hesíodoto' (lin. 315-21, Allen), lemos que Homero recitou o Hino a Apolo [...] durante a reunião dos jônios em Delos; a admiração do público foi tanta que os délios fizeram inscrever o Hino em uma tabuleta branca...”. Diante dessa constatação, torna-se imperioso questionar critérios de julgamento estético contra as manifestações artísticas das culturas de base oral, feitas de forma assistemática por críticos e autores ainda focados em um cânone eurocentrado.

Reconhecer que a oralidade é fundamento do fazer poético ocidental implica refazer o traçado de argumentações em torno de uma tendência valorativa, a partir do viés canônico, que rejeita ou estigmatiza as manifestações da oralidade como se elas não pudessem 
culminar em expressões poéticas e literárias de qualidade. Desde os primórdios, o vínculo entre poesia e oralidade promove elaborações estéticas na base da constituição artística da própria linguagem humana. É o que sugere as investigações fundadas na épica de Homero, cuja centralidade oral é evidenciada em diversos estudos, entre eles, analisamos (CABRAL, 2004).

Dessa forma, em relação dinâmica, poesia e linguagem engendram questionamentos a respeito de sua constituição e de seus constructos teóricos, uma vez que, assim como a cultura, a literatura não é estática. Do contrário, ela faculta flagrar e compreender a experiência humana temporal e espacialmente localizada para gerar arcabouços atemporais e desgeograficados.

Nessa perspectiva, a literatura reflete e permite compreender, ainda que parcialmente, a complexidade dessas afirmações. No escopo dessas considerações, Ezra Pound reitera: "Literatura é novidade que permanece novidade" (POUND, 2013, p. 36). O autor continua teorizando acerca desse tema e conclui, magistralmente: "Se alguém quiser saber alguma coisa sobre poesia, deverá fazer uma das duas coisas ou ambas. I. É, olhar para ela ou escutála. E, quem sabe, até mesmo pensar sobre ela" (POUND, 2013, p.37). Assim, convém mesmo pensar a respeito da importância das manifestações da oralidade nas representações artístico-literárias das culturas ditas de margem.

Outrossim, se essa predominância do oral, enquanto herança cultural africana e afrodiaspórica dá centralidade às histórias contadas como forma de transição da totalidade dos saberes, pela prática dos griôts; para as culturas ameríndias, essa mesma oralidade, recuperada pelas memórias ancestrais, promove o fortalecimento da identidade cultural e espiritual dos diversos povos originários, tanto brasileiros quanto ameríndios. Importante ressaltar que a contação de histórias constitui aspecto comum dessas culturas, originalmente distanciadas no espaço, mas que apresentam confluências significativas e consideráveis.

Uma digressão aos primórdios das civilizações pode ser reveladora de detalhes significativos a respeito dessa estreita relação entre linguagem, mito, literatura e poesia. Nesse ínterim, o desenvolvimento das habilidades linguísticas fomentou o potencial de criação e memorização das narrativas, em cujos usos repousa uma espécie de start up das grandes transformações promovidas pelo desenvolvimento do intelecto humano. A preponderância da literatura, enquanto arte da palavra, para garantir a sofisticação do pensamento, ao longo do processo evolutivo, fica evidenciada nessa discussão.

A esse respeito, lemos em (RIBEIRO, 2019, p. 320): 
A expansão gradual da capacidade de contar histórias e viajar mentalmente no tempo foi o combustível da explosão cultural humana nos últimos milênios. [...] O fato é que, em algum momento da nossa história recente, começamos a ser capazes de formular pequenas narrativas de futuro com base no passado. A capacidade de lembrar e relatar cadeias cada vez mais longas de pensamentos, acoplada à imaginação ativa que simboliza com facilidade, permitiu elaborar planos cada vez mais complexos com a simulação de cada vez mais variáveis, cada vez mais distante do futuro. A narração da existência humana foi expandindo a capacidade de memorização das pessoas, repertórios de memes cada vez mais ricos foram sendo construídos, e a cultura foi se fazendo e expandindo pelos relatos da vida e morte das pessoas.

O indiscutível papel da contação de histórias na formulação das primeiras narrativas, a partir das quais se desenvolveram as habilidades necessárias para a constituição de um sistema literário tal qual conhecemos hoje, é discutido por Ribeiro. $\mathrm{O}$ autor evidencia a importância dessas primeiras narrativas para a ampliação dos repertórios originais. A revelação dos temas que, segundo ele, giraram, inicialmente em torno dos relatos de vida e morte, coincidem, no caso das narrativas de morte, com o tema das imagens do regime noturno nos pressupostos de Gilbert Durand para a elaboração de sua teoria dos arquétipos.

\section{O Método Arquetipológico de Gilbert Durand}

O método arquetipológico de análise proposto pelo filósofo francês Gilbert Durand, na obra As Estruturas Antropológicas do Imaginário (1996) traz uma teoria para a epistemologia da imagem. De acordo com Durand, essa teoria apresenta a vantagem de poder ser associada às diferentes culturas e povos, de maneira sistematizada. Trata-se de ferramenta de análise fundada na inter-relação dinâmica entre as culturas, que pode ser capaz de operacionalizar relações não excludentes entre diferentes aspectos, entre eles, a oralidade e a escrita. Do excerto, podemos concluir que, a partir do emprego desses processos investigativos, torna-se possível dirimir questões valorativas e estigmatizantes nas concepções de povos e culturas diferentes.

Nas palavras do autor: “...do mesmo modo que o arquétipo era a 'matriz' de todo o imaginário, o 'sermo mythicus' torna-se a matriz de todo o discurso e, portanto, de toda a literatura, quer a oral, quer a escrita” (DURAND, 1996, p.154). Esse método, na perspectiva do filósofo, fornece um conjunto de ferramentas heurísticas para a interpretação e baseia-se na concomitância de aspectos teóricos oriundos de diversos campos do conhecimento: antropologia, psicologia, ficção e saberes populares. 
A partir dessa complexidade, Durand pensou a análise literária no encalço de um percurso antropológico, em favor do qual a temporalidade é compreendida a partir de diversas culturas, principalmente na perspectiva da finitude, da morte. Nesse aspecto, ganha relevo a busca pela compreensão de símbolos tereomórficos e de fugas simbólicas: estudo de arquétipos coletivos agrupados como imagens do regime diurno e do regime noturno. $\mathrm{Na}$ esteira dessas análises simbólicas, há a proposta de um enfoque mitológico e arquetípico da imaginação criadora, com a classificação dessas imagens recorrentes do inconsciente coletivo.

Assim, a compreensão dos arquétipos pressupõe a existência de constitutivos formadores atemporais e aespaciais, enquanto o mito é entendido como uma materialização discursiva local e espacialmente identificável, baseado naquilo que o autor denomina "bacias de recepção", com suas variações e multiplicidades. Nas palavras de Durand: “As instâncias do 'humano absoluto' são irredutivelmente plurais. Das vantagens oferecidas por esse método arquetípico, ressaltamos o fato de que todas as manifestações culturais seriam igualmente reconhecidas e validadas dentro de um sistema de representações que emerge das múltiplas culturas, de diferentes povos.

A pluralidade referida pelo autor não descarta as profundas oposições que podem ser verificadas entre o pensamento de uma e de outras vertentes culturais envolvidas nessa elaboração teórico-epistemológica. Essa complexidade é constitutiva dos esforços para a sistematização das epistemologias e dos pontos de vista expressos nas representações da literatura e da poesia que referenciam a experiência humana.

\section{As Produções da Literatura Indígena Contemporânea no Brasil}

Eliane Potiguara, Graça Graúna, Márcia Kambeba e Lia Minápoty são intelectuais cujos escritos representam, para efeito desse estudo, a produção literária feminina de autoria indígena brasileira, na contemporaneidade. Nessa análise, reiteramos o caráter enfático desse processo de rupturas nas representações literárias contemporâneas:

A compreensão dessa perspectiva teórica, no contexto de nossa pesquisa, passa pela constatação da existência e da relevância de profundas rupturas entre o modelo epistemológico de bases ocidentais e a cosmovisão dos povos indígenas. Trata-se da existência de percepções do mundo - e de modos de relacionar-se com ele - diametralmente opostos. (COSTA, 2020, p.30) 
O desafio de minorar essas oposições, a partir da adoção de um método arquetipológico de análise literária, não deve ser menosprezado, uma vez que é esperado que o conhecimento lance luz sobre as trevas do preconceito advindo da ausência dos saberes necessários para a mínima compreensão dos fatos e das dinâmicas que são constitutivas da complexidade das experiências individuais e coletivas no universo. Acreditamos que privilegiar a postura de investigação científica de pesquisadores e pesquisadoras pode contribuir com esse processo desafiador, tornando factível o equacionamento de tais polêmicas.

O neurofisiologista Sidarta Ribeiro, na obra O Oráculo da Noite: A História e a Ciência do Sonho (2019, p.41), acrescenta elementos interessantes ao debate, quando reafirma, em sua obra:

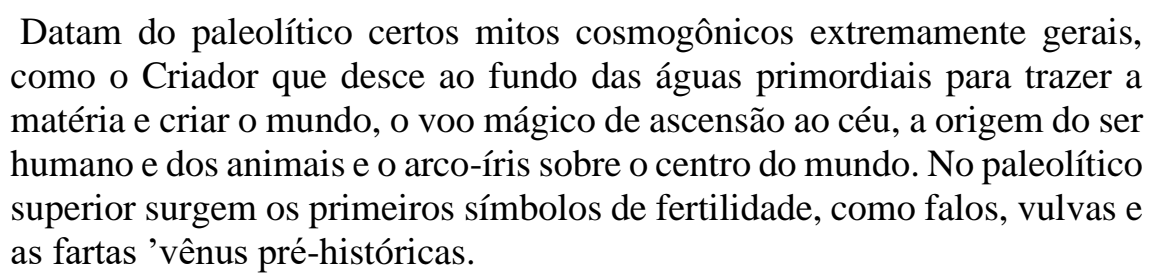

As literaturas de autoria indígena e afro-brasileira trazem riqueza de abordagens arquetípicas, com generosa oferta de imagens e de símbolos, em consonância com as formulações teóricas de (RIBEIRO, 2019). A escrita das mulheres indígenas, como exemplo, vem carregada dessas imagens.

Entre as escritoras indígenas contemporâneas citadas nesse artigo, destaca-se a poeta Maria das Graças Ferreira, a Graça Graúna, professora e ativista engajada no movimento de resistência da Literatura Indígena Contemporânea no Brasil. Do povo Potiguara vem essa intelectual que é natural da pequena cidade de São José do Campestre, no Rio Grande do Norte. Graça Graúna tem carreira acadêmica e artística consolidada. Ela, como muitos outros intelectuais indígenas, lança mão das mídias digitais para divulgação de sua produção intelectual e literária. Assim, estabelece contato direto e frequente com o seu público. A escritora também mantém um blog pessoal que é alimentado frequentemente com sua produção poética, além de publicações sobre outros temas que versam sobre literaturas, pesquisa e militância pelas causas indígenas e pelo meio ambiente.

Ao analisar a obra Criaturas de Nhanderu (2010), de Graça Graúna, (COSTA, 2020, p. 48-49) exemplifica:

... a saga mulher pássaro cujo canto foi aprisionado. Para não morrer de tristeza, ela retorna, em pensamento, à água, para embebedar-se no poder de sua essência feminina: "[...] ela mergulha nos rios e gralha forte um canto que tem a força da flecha que atinge certeira o coração dos 
malfeitores". (GRAÚNA, 2010, p. 23). Além desse canto flecha, capaz de desestabilizar os princípios da hegemonia masculina, a mulher pássaro mistura-se à paisagem, tingindo o céu com nuvens escuras para que o mundo não esqueça sua dor, para que a humanidade ouça o seu canto e para que as mulheres lutem por sua liberdade e por seus direitos. Assim, os efeitos dessas lutas poderão beneficiar o conjunto das mulheres que convivem com o silenciamento de suas vozes e que se encontram engaioladas, em quaisquer tipos de prisões pelo mundo afora.

A recorrência dos mitos na escrita dessas mulheres indígenas está presente também na obra da jovem intelectual do povo Maraguá, do Amazonas, Lia Minápoty Aripunaguá. Ela é uma das lideranças femininas do seu povo, trabalha com a educação das crianças e representa a Associação de Mulheres Maraguá (AMIMA). Além disso, é artista plástica especializada em grafismos e coleciona plantas e borboletas. Em sua obra Yara é Vida (2018), a moça retoma o mito da mãe das águas.

Ao ficcionalizar a presença dessa divindade tão importante para o seu povo, a escritora acrescenta elementos para alertar as novas gerações a respeito da necessidade da preservação dos recursos hídricos para o equilíbrio da vida na terra e para o bem-estar das pessoas. Nas palavras da autora:

"Yara é vida" surgiu da imaginação conjunta entre mim e m eu tio Elias, também escritor e grande contador de histórias. Participei da ideia de escrever um livro que tratasse sobre água, o valor que ela tem para o nosso povo e inclusão na história de uma entidade bem bonita e do bem, como tantas que povoam a mitologia do povo Maraguá. (MINÁPOTY, 2018)

A escritora explicita a importância desse mito para o seu povo e expressa sua admiração pela beleza e pelos valores dessa divindade. A respeito do mito que inspirou o livro Yara é Vida (2018):

Segundo a lenda que inspirou a obra, a bela Guayara, senhora das águas é mulher de grande coração e beleza única. Conhecida como Yara, na mitologia tupi, ela vive nos rios e lagos da Amazônia. Quando sobe à superfície, dedica-se a cuidar da natureza e está sempre pronta a ajudar as pessoas (COSTA, 2020, p.78,79).

Temas do universo feminino são referenciados nas obras das intelectuais indígenas de forma intensa e poética ressaltando a cultura, as memórias ancestrais, e os mitos fundadores de cada povo. A escrita dessas mulheres dá relevo também às lutas dos povos originários por direitos como a valorização de suas culturas, o respeito à propriedade intelectual indígena, a saúde das populações indígenas, a proteção contra violências e contra as invasões às aldeias e a defesa dos territórios sagrados. Dessa forma, essa literatura exige, de seus leitores, uma 
tomada de consciência e, não raro, de posição em relação aos temas abordados, bem como às lutas desses povos.

Ressaltamos o reconhecimento da importância da água para a criação e manutenção da vida, em diferentes culturas, e a celebração em caráter místico, por meio das crenças. Assim, nas culturas africanas e afro-brasileiras também é prática comum cultuar a divindade das águas: Yemanjá é a rainha do mar. Em homenagem a ela, milhares de pessoas lançam flores ao mar, durante a celebração do Reveillón, todos os anos, em diversas localidades.

Outra intelectual com grande destaque e reconhecimento no cenário artístico e literário, na atualidade, é Márcia Kambeba. Filha do povo Omágua/Kambeba, Márcia Vieira da Silva é da aldeia tikuna, em Belém do Solimões. Aos oito anos de idade, mudou-se para a cidade São Paulo de Olivença, no município do Alto Solimões que, segundo ela, no passado, já foi aldeia do seu povo Kambeba. A artista possui múltiplas habilidades e atua em diversas áreas: Ciências Humanas, Educação, Linguística e Artes. Além disso, é geógrafa, fotógrafa, escritora, poeta, compositora, atriz, cantora e ativista. Mestra em Geografia, desenvolveu estudos na área da Antropologia Cultural e, atualmente, está cursando doutorado.

O estudo da poética de Márcia Kambeba, evidencia uma voz lírica engajada nos processos culturais, sociais e políticos da atualidade, ao mesmo tempo em que retoma com bastante intensidade a sabedoria ancestral do seu povo, em profunda reverência à ancestralidade e à espiritualidade indígenas. Os versos do poema "Mergulho Profundo", ora transcritos, ilustram bem os aspectos citados:

Mergulhei no rio profundo

Rio de espiritualidade

Rio que me traz esperança

Rio de ancestralidade.

Nas profundezas ouvi

O canto dos pajés

A beleza da mãe d'água

Nas águas escuras dos igarapés.

Mergulho no rio e vou fundo

Em busca do meu sagrado

E vejo no rio espelhado

A imagem do meu eu.

Sem pressa voltarei

Sou filha da mãe mata

Minha pele retrata

A cor que dela peguei

Pachamama! 
H. R. Costa O método arquetipológico e o estudo das literaturas indígenas e afrodiaspóricas

Com a lama me abracei.

(KAMBEBA, 2018, p. 28).

O texto é parte de um conjunto que compõe o primeiro livro de poemas da autora, $A y$ Kakiry Tama: eu moro na cidade (2018). O livro apresenta ao leitor um sujeito lírico feminino que se divide em identidades plurais. Voz poética indígena, em contexto urbano, verbaliza experiências subjetivas particularizadas e vivências da aldeia, de forma a expressar a complexidade dessa condição transitória que afeta as identidades indígenas brasileiras contemporâneas, em razão das diásporas dos povos indígenas pelo interior do território brasileiro.

No poema, acontece o encontro com o sagrado, nas profundezas do igarapé, em presença dos pajés, e de divindades como a mãe d'água. Após mergulhar profundamente, ouve o canto dos pajés e se depara com sua própria imagem: "E vejo no rio espelhado/ A imagem do meu eu." Então, retorna à superfície, "sem pressa", assimila e elabora a identificação com o barro original, com a lama, que lhe tingiu a pele.

As diferentes cosmovisões são marcadas pelo pertencimento e pelas vivências individuais, determinadas pela cultura e pelas subjetividades de cada povo. Assim, interessa esclarecer que, para as epistemologias indígenas e afrodescendentes, há conceitos e relações díspares na relação com os princípios da epistemologia ocidental de base eurocentrada. Assim, lemos em artigo sobre poéticas indígenas e afro-brasileiras:

Para as subjetividades de muitos desses povos, não existem mitos, pelo menos, não no sentido trazido pelas concepções ocidentalizadas. Esses povos assumem suas narrativas cosmogônicas como histórias de pertencimento e de identidade que os definem enquanto povo, enquanto nações indígenas, com características e especificidades muito peculiares de cada grupo. Dessa forma, a identidade feminina indígena, no poema, reafirma-se e se fortalece na identificação com a mãe terra, a partir do encontro com o sagrado em um mergulho nas águas profundas. (COSTA, 2021, p.154)

Na escuridão misteriosa das águas profundas, a voz lírica se nutre de sua força ancestral e se depara com o seu eu mais profundo, em conexão perfeita com a sua ancestralidade indígena e no contato direto com a natureza, da qual se reconhece parte integrante. Dessa relação visceral com a natureza vem a percepção subjetiva desses povos. 
H. R. Costa O método arquetipológico e o estudo das literaturas indígenas e afrodiaspóricas

\section{As Produções da Literatura Afrodiaspórica no Brasil}

No campo da produção literária e poética das culturas afrodiaspóricas, como representante das intelectuais negras, no Brasil, a escritora Conceição Evaristo, mineira de Belo Horizonte, conquistou merecido respeito e é reconhecida como uma das principais intelectuais no cenário atual. Dona de uma poética rica, variada e intertextual, a autora, que venceu as agruras de uma infância pobre e tornou-se Doutora em Literatura Comparada, desenvolve um trabalho admirável com a escrita e a crítica literárias. Poeta de mão cheia e narradora respeitada, transita com desenvoltura pelos diversos temas que reverberam no contexto da sociedade brasileira atual.

Evaristo tem uma agenda concorridíssima e se desdobra para ministrar palestras, conceder entrevistas e participar de eventos literários e de militância do feminismo negro. Seus textos admiráveis tematizam a complexidade das vivências do povo negro, principalmente das mulheres. E, se ela aborda em seus escritos, temas da crítica social, como a pobreza, a fome, a violência; há também lugar para a celebração do amor, da paixão e do desejo. E até mesmo da solidão das mulheres negras, com as especificidades de sua sexualidade e de seus afetos.

Do livro Poemas da Recordação e outros Movimentos (2021), lemos os versos do poema "Meu rosário", abaixo transcritos:

Meu rosário é feito de contas negras e mágicas.

Nas contas de meu rosário eu canto Mamãe Oxum e falo

padres-nossos, ave-marias.

Do meu rosário eu ouço os longínquos batuques do meu povo

e encontro na memória mal-adormecida

as rezas dos meses de maio de minha infância.

As coroações da Senhora, onde as meninas negras, apesar do desejo de coroar a Rainha,

tinham de se contentar em ficar ao pé do altar lançando flores.

As contas do meu rosário fizeram calos nas minhas mãos, pois são contas do trabalho na terra, nas fábricas, nas casas, nas escolas, nas ruas, no mundo.

As contas do meu rosário são contas vivas.

(Alguém disse que um dia a vida é uma oração, eu diria porém que há vidas-blasfemas).

Nas contas de meu rosário eu teço entumecidos sonhos de esperanças. 
Nas contas do meu rosário eu vejo rostos escondidos por visíveis e invisíveis grades e embalo a dor da luta perdida nas contas do meu rosário.

Nas contas de meu rosário eu canto, eu grito, eu calo.

Do meu rosário eu sinto o borbulhar da fome

No estômago, no coração e nas cabeças vazias.

Quando debulho as contas de meu rosário, eu falo de mim mesma em outro nome.

E sonho nas contas de meu rosário lugares, pessoas, vidas que pouco a pouco descubro reais.

Vou e volto por entre as contas de meu rosário, que são pedras marcando-me o corpo-caminho.

E neste andar de contas-pedras, o meu rosário se transmuda em tinta, me guia o dedo, me insinua a poesia.

E depois de macerar conta por conto do meu rosário, me acho aqui eu mesma e descubro que ainda me chamo Maria. (EVARISTO, 2021, p.43)

O rosário de contas negras carrega a simbologia da espiritualidade ancestral. Por meio de suas contas, a voz poética canta "Mamãe Oxum” e as rezas (padres-nossos e ave-marias) convertendo-o em representação viva do sincretismo religioso. As contas lembram possibilidades de trabalho, de sonhos, de visões de lugares outros, de cantos, de gritos, de resistências, de silêncios e até mesmo da própria escrita. O poema não deixa de flagrar a condição de subalternidade das meninas negras que, desejando "coroar a rainha" são forçadas a permanecerem "ao pé do altar".

A celebração do culto à orixá mãe, por meio das contas do rosário é emblemática da resistência afrodiaspórica contra a dominação espiritual e simbólica, através do jugo físico e material e da opressão pelo racismo. É também pelas contas do rosário que o resgate da sabedoria ancestral ocorre, personificada, nos versos, pela audição dos sons do batuque. A partir das diversas visões trazidas pelas contas vivas do rosário, a voz lírica constrói a sua resistência que culmina no projeto revolucionário da escrita de uma mulher negra.

Nessa perspectiva, a leitura do poema "Força Ancestral", da intelectual e artista negra Cristiane Sobral oferece elementos importantes para o conjunto de nossa análise. A respeito dessa autora, explicitamos: Cristiane Sobral é poeta, professora e atriz. Nasceu no Rio de Janeiro, em 1974 e iniciou seu trabalho na dramaturgia com apenas dezesseis anos de idade. 
Estudou na Universidade de Brasília e tornou-se a primeira atriz negra com formação superior.

O envolvimento com os temas sociais em sua atuação profissional se reflete na escrita poética e se manifestou, de forma mais perceptível a partir das publicações coletivas nos Cadernos Negros, iniciadas no volume 23, no ano 2000. Depois disso, ela participou de diversas outras edições. Além disso, atuou como crítica teatral escrevendo para revistas especializadas.

Não vou mais lavar os pratos foi sua primeira publicação individual, em 2010. Espelhos, miradouros, dialéticas da percepção - seu segundo livro, é de 2014. Também no ano de 2014, publicou sua terceira obra: Só por hoje vou deixar o meu cabelo em paz. Em 2017, a autora trouxe ao público a obra Terra negra, com setenta e quatro poemas, em que apresenta traçados referentes ao universo feminino.

Do conjunto de textos do livro Terra negra (2017), transcrevemos os versos do poema "Força Ancestral”":

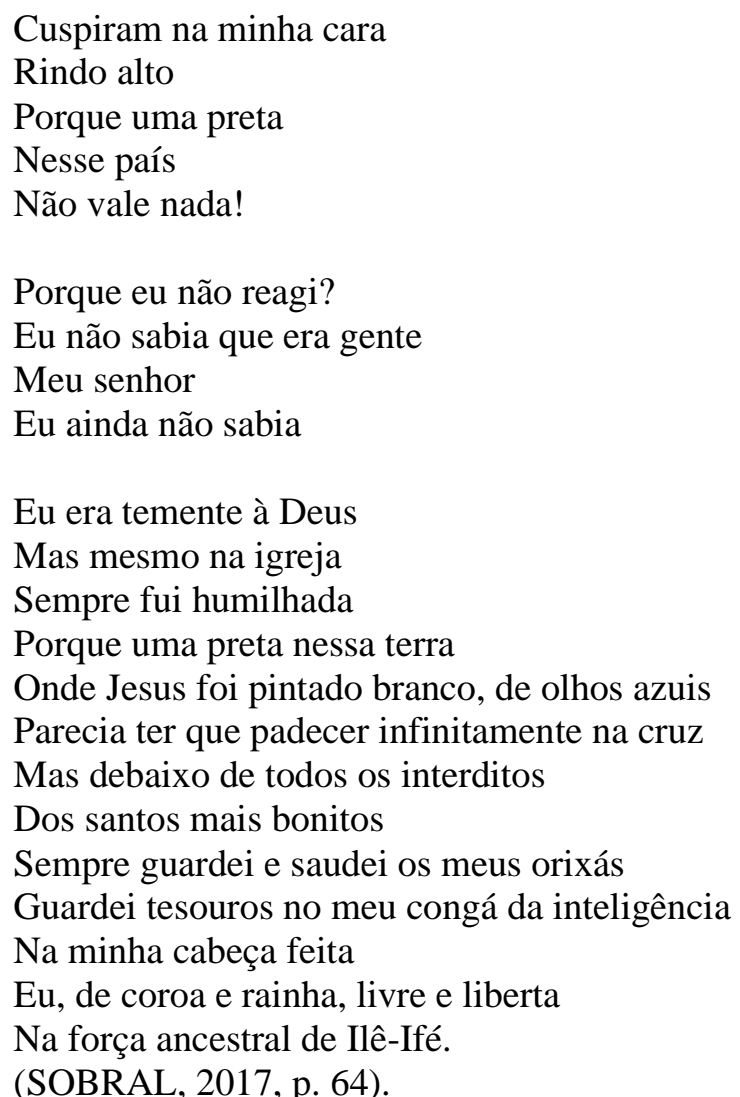

O texto possui fundamentos na oralidade e no contradiscurso. Há, na superfície textual, a presença de um interlocutor, identificado pela fórmula de tratamento: "Meu senhor". Considerando o peso do passado escravocrata para as subjetividades negras, principalmente 
para as mulheres negras brasileiras: colonialismo, falocentrismo e sociedade escravagista, identifica-se o possível destinatário da argumentação construída pela voz lírica.

Nesse conjunto argumentativo, a voz poética tenta explicitar as razões pelas quais não esboçou reação contra o abuso: "Eu não sabia que era gente/ Eu ainda não sabia”. Em outras palavras, o rapto das subjetividades negras, expresso pela subtração dos bens e dos valores essenciais como: pátria, lar, tradição, língua, nome, família, religiosidade, pertencimento, dignidade, enfim, tudo que, aos escravizados, fora roubado.

Em contrapartida, emergem do texto de Sobral com intensa potência poética, os elementos da espiritualidade: "Guardei tesouros no meu congá da inteligência”. A respeito desse aspecto, Sodré (2017, p. 204) ressalta o papel do culto milenar aos orixás, como estratégia para a reafirmação étnica e identitária dos indivíduos negros: “...mas as elites negras, postas à margem do reconhecimento pelo demos hegemônico, ensaiaram formas de afirmação étnica, em que a religiosidade assume o primeiro plano". Percebe-se, a partir da leitura do poema, que a força que sustenta o sujeito lírico é a força da espiritualidade ancestral.

Por essa razão, ao final do poema, o eu poético toma posse de seu poder por força da ancestralidade, resgatada e fortalecida nessa vivência epifânica do sagrado ancestral: "Na força ancestral de Ilê-Ifé". Pela presença das divindades africanas, dos orixás, evoca-se a força de resistência do povo preto contra a opressão racista.

De semelhante forma, o pertencimento pelos laços com o sagrado fortalece a identidade dos povos afrodiaspóricos. Nessa perspectiva, a ancestralidade e a espiritualidade se unem e se complementam dialeticamente para fortalecer as bases da resistência negra contra os processos do jugo e da dominação, iniciados a partir do processo escravocrata, desde o período colonial, e que se perpetua, por força do preconceito, até os dias atuais. Em outros termos, no contexto do poema, a voz lírica reitera: "sempre saudei os meus orixás".

Da produção literária voltada para o público infantil, a escritora negra brasileira contemporânea Kiusam de Oliveira celebra as narrativas do povo africano Iorubá e afrobrasileiro, ao apresentar aos leitores histórias de princesas negras e suas trajetórias para se tornarem rainhas, em seu livro OMO-OBA: Histórias de princesas (2009). Nascida Kiusam Regina de Oliveira, a autora, natural de Santo André-SP, é professora, contadora de histórias e doutora em Educação pela Universidade de São Paulo. A partir de seus escritos, busca valorizar a autoimagem das pessoas negras, sobretudo das crianças. 
No primeiro conto do livro, a autora resgata a narrativa ancestral: Oiá e o búfalo interior. Ela inicia o conto, evidenciando a beleza, a graça, a genialidade e a determinação da princesa Oiá. Ao final dessa trama, a narradora enaltece a força interior de cada mulher. Nas palavras de Kiusam de Oliveira:

Toda menina, toda mocinha e toda mulher têm dentro de si a força e o poder de um animal selvagem sagrado que, em certos momentos devem ser colocados para fora, deem explodir para o universo com a mensagem de que fazemos parte de tudo isto. Quando colocamos essa força para fora, muitos meninos e meninas, mocinhos e mocinhas, homens e mulheres não compreendem e, por isso, devemos mantê-la em segredo. (OLIVEIRA, 2009, p.15)

A autora desenvolve um trabalho importante com o seu projeto de escrita literária, buscando, através de suas narrativas, fomentar a cura das feridas emocionais de milhões de pessoas negras que sofrem com o preconceito, sobretudo das crianças afrodescendentes que, normalmente, são vítimas de bullying nas escolas. E, na maioria das vezes, não encontram apoio para lutarem contra esse tipo de abuso racista. Paralelamente, ela resgata narrativas do universo das culturas ancestrais, enriquecendo o arcabouço teórico e cultural de seus leitores e fortalecendo as suas subjetividades para os enfrentamentos comuns diante de uma sociedade ainda racista e preconceituosa.

\section{Considerações Finais}

As literaturas indígenas e afrodiaspóricas apresentam riqueza de representações e de símbolos das suas culturas de origem. Entretanto, muitas vezes, não são devidamente valorizadas no conjunto das manifestações literárias. Esse fato reflete o desconhecimento acerca dessas manifestações da arte da escrita, ao mesmo tempo, em que são negadas e silenciadas por causa de preconceitos criados para supervalorizar narrativas supostamente mais representativas do conceito usual de nação. Nesse sentido, um método de análise isento de tais estigmas e capaz de assimilar as diferenças culturais sem descaracterizá-las, conforme a proposta do filósofo Gilbert Durand, traria contribuições significativas para o contexto dos estudos de literatura e de linguagem.

Há, entretanto, questões subjacentes não menos importantes a serem consideradas que extrapolam o contexto artístico, interpretativo e literário e motivam polêmicas como a que se criou, artificialmente, em torno da supervalorização da escrita na abordagem das poéticas, conforme procuramos explicitar no início desse artigo. A importância de questões dessa 
natureza não deve ser minimizada, sob pena de se cometerem equívocos interpretativos que comprometam a lisura do trabalho da crítica literária.

Vale ressaltar que a adoção de posturas pautadas em preconceitos, seja cultural, ideológico ou linguístico por parte do pesquisador, pode comprometer qualquer trabalho de análise e crítica que se pretenda fazer em torno de produções literárias ou poéticas, independente de sua inserção em circuitos, sejam eles considerados canônicos ou não.

\section{Referencias}

DURAND, Gilbert. As estruturas antropológicas do imaginário. 3. ed. São Paulo: Martins Fontes, 2002.

CABRAL, Luiz Alberto Machado. O hino homérico a Apolo. Cotia,SP: Ateliê Editorial; Campinas: Editora da Unicamp, 2004.

COSTA, Heliene Rosa da. Identidades e Ancestralidades na escrita das mulheres indígenas na poética de Eliane Potiguara. Tese (Doutorado em Estudos Literários). Instituto de Letras e Linguísticas-ILEEL / Programa de Pós-Graduação em Estudos Literários-PPLET da Universidade Federal de Uberlândia, 2020. (dói https://repositorio.ufu.br/handle/123456789/29255).

COSTA, Heliene Rosa da. Poéticas de Cristiane Sobral e Márcia Kambeba: vivências do sagrado como resistência. Revista Igarapé, Porto Velho (RO), v. 14, n. 2, p.139-160, 2021. Disponível em: https://periodicos.unir.br/index.php/igarape/article/view/5996. (acesso em agosto-2021).

EVARISTO, Conceição. Poemas da Recordação e outros Movimentos. $6^{\text {aed. Rio de }}$ Janeiro: Malê, 2021.

GRAÚNA, Graça. Criaturas de Nhanderu. $1^{a}$ ed. Barueri-SP: Editora Amarylis, 2010.

KAMBEBA, Márcia Wayna. Ay Kakiry Tama: eu moro na cidade. 2. ed. São Paulo: Pólen, 2018.

MINAPOTY, Lia. YAGUAKÃ, Elias. Yara é vida. São Paulo: Editora Kazuá, 2019.

OLIVEIRA, Kiusam. OMO-OBA: Histórias de princesas. Belo Horizonte: Mazza Edições, 2009.

POUND, Esra. ABC da Literatura. Tradução de José Paulo Paes e Augusto de Campos. $12^{\mathrm{a}}$ ed. São Paulo: Cultrix, 2013. 
H. R. Costa O método arquetipológico e o estudo das literaturas indígenas e afrodiaspóricas

RIBEIRO, Sidarta. O Oráculo da Noite: a história e a ciência do sonho. $1^{\text {a }}$ ed. São Paulo: Companhia das Letras, 2019.

SOBRAL, Cristiane. Terra Negra. Rio de Janeiro: Malê, 2017.

SODRÉ, Muniz. Pensar Nagô. Petrópolis/RJ: Vozes, 2017.

Artigo recebido em: 09.10.2021

Artigo aceito para publicar em: 04.01.2022 